\title{
Scrap Tire Ashes in Portland Cement Production
}

\author{
Mónica Adriana Trezza* , Alberto Néstor Scian ${ }^{\mathrm{b}}$ \\ ${ }^{a}$ Facultad de Ingeniería - UNCPBA \\ Av. del Valle 5737 (7400) Olavarría, Argentina \\ ${ }^{\mathrm{b}}$ Centro de Tecnología de Recursos Minerales y Cerámica, CONICET La Plata - UNLP \\ Cno. Centenario y 506 (1897) Gonnet, Argentina
}

Received: August 10, 2009; Revised: November 12, 2009

\begin{abstract}
Scrap tires are not considered harmful waste, but their stocking and disposal are a potential health and environmental risk. Properly controlled calcinations at high temperatures make tire combustion an interesting alternative due to its high calorific power, comparable to that of fuel-oil. Consequently, using them as an alternative combustible material in cement kilns makes it possible to give it a valuable use. However, it remains to be assured whether the impurities added to the clinker through these fuels do not affect its structure or properties.This paper shows the studies carried out on different clinkers under laboratory conditions with different levels of addition of scrap tire ashes, added by partially replacing traditional fuel in cement kilns.
\end{abstract}

Keywords: portland cement clinker, alternative fuels, scrap tires, $\mathrm{ZnO}$

\section{Introduction}

In 1839 Charles Goodyear discovered that natural rubber could be joined with sulfur (using $\mathrm{ZnO}$ as catalyst) to prevent chains from sliding. This process was called vulcanization and led the way in manufacturing tires. In Argentina more than twelve million of car tires and one hundred thirty thousand of agricultural equipment are produced according to the National Institute of Statistics and Census ${ }^{1}$ (INDEC) 2006-2007 periods (2008), which implies an important amount of annual waste. Scrap tires are not meant to be hazardous waste; nevertheless, their stocking and disposal are risky to the health and the environment.

Despite the widespread use of tires as additives in concretes ${ }^{2-4}$, the present study explores the effect that the use of tires as an alternative fuel in clinker kilns has on the clinker structural characteristics and on its later hydration.

The main raw materials used in the manufacture of tires are rubbers, steel, textiles and many additives such as: carbon black, oils, zinc oxide (cadmium activated), titanium dioxide, sulfur, silica, phenolic resins and fatty acids. This composition allows the use of scrap tires as a residual energy source, practice dating from 1975.

It has been tested that scrap tires, compared with coal, have less moisture and noticeably more fuel material and they fix less carbon. Also, scrap tires calorific content is 10 to $16 \%$ higher $^{5}$. Scrap tires are an excellent fuel for cement kilns. In extremely high temperatures, the kiln oxidizing atmosphere and relatively long gas residence times encourage complete combustion of scrap tires. This precludes products of incomplete combustion (PICs) or black smoke from being released to the environment ${ }^{6}$.

However, the vulcanization process crosses the polymer chains with sulfur bridges, enhancing its properties. This requires the use of $\mathrm{ZnO}$ as catalyst. The addition of $\mathrm{ZnO}$ to control the vulcanization rate results in high zinc content in tires ashes, which would be incorporated to the cementitious matrix through the clinkering process. Metals such as $\mathrm{Pb}$ and $\mathrm{Tl}$ can also be found in ashes, but in a lower proportion. Although it has been reported that the addition of $\mathrm{Zn}$ does not affect the formation of the clinker phases even in concentrations 10 or 20 times higher than the ones observed in a normal clinker ${ }^{7}$, it is well known that $\mathrm{Zn}$ and $\mathrm{Pb}$ contents increase the setting time in Portland cement hydration ${ }^{8-11}$. Since tires are extensively used as an alternative fuel in the Portland cement industry, it is essential to study the effect these metals have, together and in actual percentages, on the products and on the hydration rate of Portland cement. The $\mathrm{ZnO}$ effect is especially interesting because $80-90 \%$ of it will be placed in the clinker and only the rest in the dust ${ }^{12}$, whereas $\mathrm{Pb}$, Ti and other materials of high volatility probably vaporize at clinkering temperature ${ }^{13}$.

Studies on different clinkers elaborated under laboratory conditions, with different addition levels of scrap tire ashes just as they would be added during the partial replacement of the traditional fuel, will be presented in this work. Replacement percentages were maintained within the limits accepted in industrial plants. The results will be compared with those corresponding to a control clinker obtained without this kind of addition.

\section{Experimental Program}

\subsection{Materials}

\subsubsection{Raw material}

The raw material used in this work corresponds to an industrial mixture provided by a local cement industry. It was chemically analyzed by X-ray fluorescence, as it is shown in Table 1.

The material was characterized by XRD (Figure 1). Most crystalline phases observed were $\mathrm{CaCO}_{3}$ (calcite) and $\mathrm{SiO}_{2}$ (quartz). Muscovite $\left[\mathrm{KAl}_{2} \mathrm{Si}_{3} \mathrm{AlO}_{10}(\mathrm{OH})_{2}\right]$ was detected among minor crystalline constituents.

\subsubsection{Tire ashes}

Tire ashes were obtained by calcinations chips of used scrap tires at $1000{ }^{\circ} \mathrm{C}$ until constant weight. The chemical analysis of the main compounds of ashes expressed as oxides is shown in Table 2; it also includes the content of the metals mostly found in them. 
Table 1. Chemical composition of the raw material, as oxides (\%w/w).

$\begin{array}{cc}\mathrm{CaO} & 43.52 \\ \mathrm{SiO}_{2} & 14.28 \\ \mathrm{Al}_{2} \mathrm{O}_{3} & 3.12 \\ \mathrm{Fe}_{2} \mathrm{O}_{3} & 2.37 \\ \mathrm{~K}_{2} \mathrm{O} & 0.69 \\ \mathrm{Na}_{2} \mathrm{O} & 0.03 \\ \mathrm{SO}_{3} & 0.49 \\ \mathrm{LOI} & 34.9 \\ \text { Other nd } & 0.6\end{array}$

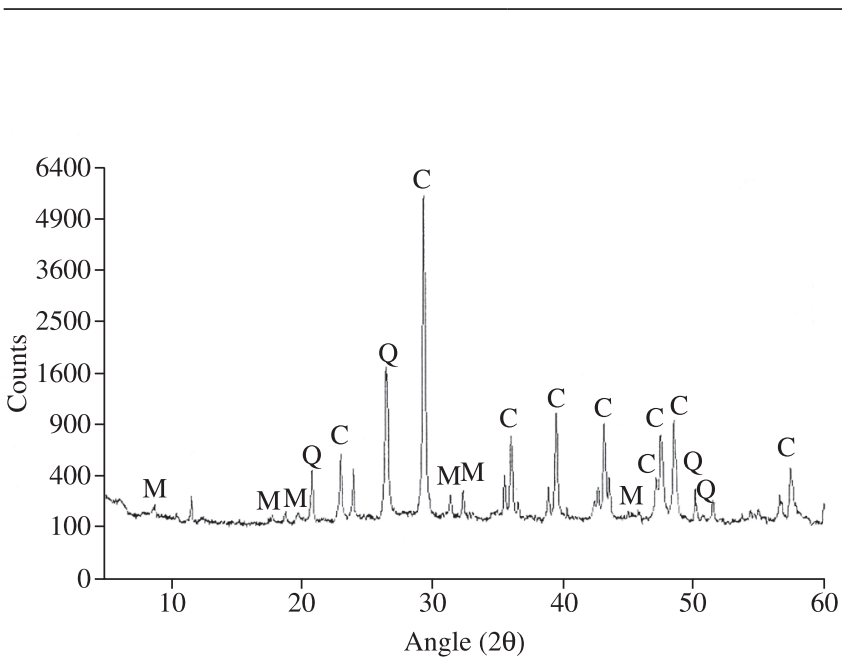

Figure 1. X-ray power diffraction of raw material.

The characterization performed by XRD detected $\mathrm{CaSO}_{4}$ such as anhydrite and $\mathrm{ZnO}$ as the main ashes compounds. $\mathrm{CaO}, \mathrm{CaCO}_{3}$ and $\mathrm{Ca}(\mathrm{OH})_{2}$ were also found.

\subsection{Samples preparation and test techniques.}

\subsubsection{Samples preparation}

Usually, alternative fuels replace until $20 \%$ of traditional ones. For each $100 \mathrm{~kg}$ of clinker, about $10 \mathrm{~kg}$ of equivalent fuel in carbon is required; then, up to $2 \mathrm{~kg}$ of these alternative fuels will be used.

According to these replacement levels, different mixtures of crude dust were prepared for this study and the remaining tire ashes after total combustion were directly added as it is described in Table 3 . The N20 sample was prepared assuming that all ashes remaining after the highest replacement of traditional fuel by the alternative one were added to the clinker. N10 had half of the addition, and N30 had an excess in order to detect tendencies.

The mixture composed by raw materials and tire ashes were mechanically mixed, pelletized and then clinkered in an electric muffle furnace with a heating rate of $10{ }^{\circ} \mathrm{C} / \mathrm{min}$ up to a final temperature of $1450{ }^{\circ} \mathrm{C}$, and kept at that temperature for an hour. Cooling rate $\left(20^{\circ} \mathrm{C} / \mathrm{min}\right.$ until $1200^{\circ} \mathrm{C}$, them quenching to ambient temperature) was also controlled to ensure that the suitable hydraulic phases remain.

\subsubsection{Test techniques}

The different synthesized clinkers were milled in a Herzog HSM 100 oscillating mill with a vanadium steel chamber. Equal quantities of each clinker were milled at equal times in order to make the
Table 2. Chemical analysis of the tire ashes (\% w/w).

\begin{tabular}{lclc}
$\mathrm{SiO}_{2}$ & 14.1 & $\mathrm{P}_{2} \mathrm{O}_{5}$ & $<0.01$ \\
$\mathrm{Al}_{2} \mathrm{O}_{3}$ & 2.7 & $\mathrm{Na}_{2} \mathrm{O}$ & $<0.01$ \\
$\mathrm{Fe}_{2} \mathrm{O}_{3}$ & 1.1 & $\mathrm{~K}_{2} \mathrm{O}$ & $<0.01$ \\
$\mathrm{TiO}_{2}$ & $<0.01$ & $\mathrm{SO}_{3}$ & 1.2 \\
$\mathrm{CaO}$ & 47.0 & $\mathrm{MnO}$ & $<0.01$ \\
$\mathrm{MgO}$ & 0.7 & $\mathrm{ZnO}$ & 33.1 \\
$\mathrm{Chromium}$ & $94 \mu \mathrm{g} \cdot \mathrm{g}^{-1}$ & Cadmium & $6 \mu \mathrm{g} \cdot \mathrm{g}^{-1}$ \\
$\mathrm{Nickel}$ & $92 \mu \mathrm{g} \cdot \mathrm{g}^{-1}$ & Lead & $184 \mu \mathrm{g} \cdot \mathrm{g}^{-1}$ \\
- & - & Talium & $<2 \mu \mathrm{g} \cdot \mathrm{g}^{-1}$ \\
\hline
\end{tabular}

Table 3. Replacement percentage and denomination, of the samples.

\begin{tabular}{cccccc}
\hline Denomination & N0 & N5 & N10 & N20 & N30 \\
\hline$\%$ de replacement & 0 & 5 & 10 & 20 & 30 \\
\hline
\end{tabular}

test comparative. Milling time was selected to maintain the specific surface within the range used in normal cements.

The following tests were performed on the clinkers milled: specific surface measurement by the Blaine method, temperature measurement by Pyrometric Cone Equivalent (PCE). X-ray Diffractions (XRD) were performed in a difractometer PHILIPS ${ }^{\circledR}$ PW 3710 with $\mathrm{Cu}-\mathrm{K} \alpha$ radiation.

Clinkers were hydrated with $w / c=0.4$, at different study ages; pastes were milled in the presence of acetone and analyzed by XRD. The study was completed following up the early hydration using differential calorimetry. Cylindrical probes (diameter $1.5 \mathrm{~cm}$ high $1.8 \mathrm{~cm}$ ) were also prepared to determine compressive strength after 7 and 28 days using J.J. Instruments press. Lixiviation tests were carried out according to the Toxicity Characteristics Leaching Procedures (TCLP).

\section{Results and Discussion}

\subsection{Clinker analysis}

\subsubsection{XRD analysis}

Clinkers obtained in the presence of tire ashes (N5 to N30) and the reference samples (N0), were characterized by XRD. The diffractograms obtained for the different clinkers were comparatively analyzed. All typical phases of Portland cement could be identified, such as $\mathrm{C}_{3} \mathrm{~S}, \mathrm{C}_{2} \mathrm{~S}$ and $\mathrm{C}_{3} \mathrm{~A}^{*}$.

The diffractograms obtained of the clinkers synthesized in the presence of tire ashes in the specified proportions did not show the formation of new phases or compounds that could be detected by this technique. However, to N5 is a greater height of the main peaks $\mathrm{C}_{3} \mathrm{~S} / \mathrm{C}_{2} \mathrm{~S}$. This increase is consistent with a slight decrease from the background of the spectrum, which is generally associated with a reduced content of glassy phase. Figure 2 shows N0, N5 and N30 X-ray diffractograms comparatively.

Based on the above, the N5 sample shows a higher crystallinity than the N0 reference and the whole series with tire ashes added;

*The conventional nomenclature in the chemistry of cement be used: $\mathrm{C}=\mathrm{CaO}$, $\mathrm{S}=\mathrm{SiO}_{2}, \mathrm{~A}=\mathrm{Al}_{2} \mathrm{O}_{3}, \mathrm{H}=\mathrm{H}_{2} \mathrm{O}$ 
however, it does not show a tendency that could be correlated with the percentage added (N5 $>\mathrm{N} 20>\mathrm{N} 30>\mathrm{N} 10)$.

It is important the inversion of the relative intensities (compared with N0) of the main peaks of silicates found for $d=2.6046(2 \theta=34.405,100 \%), d=2.7433(2 \theta=32.615,74 \%)$ and
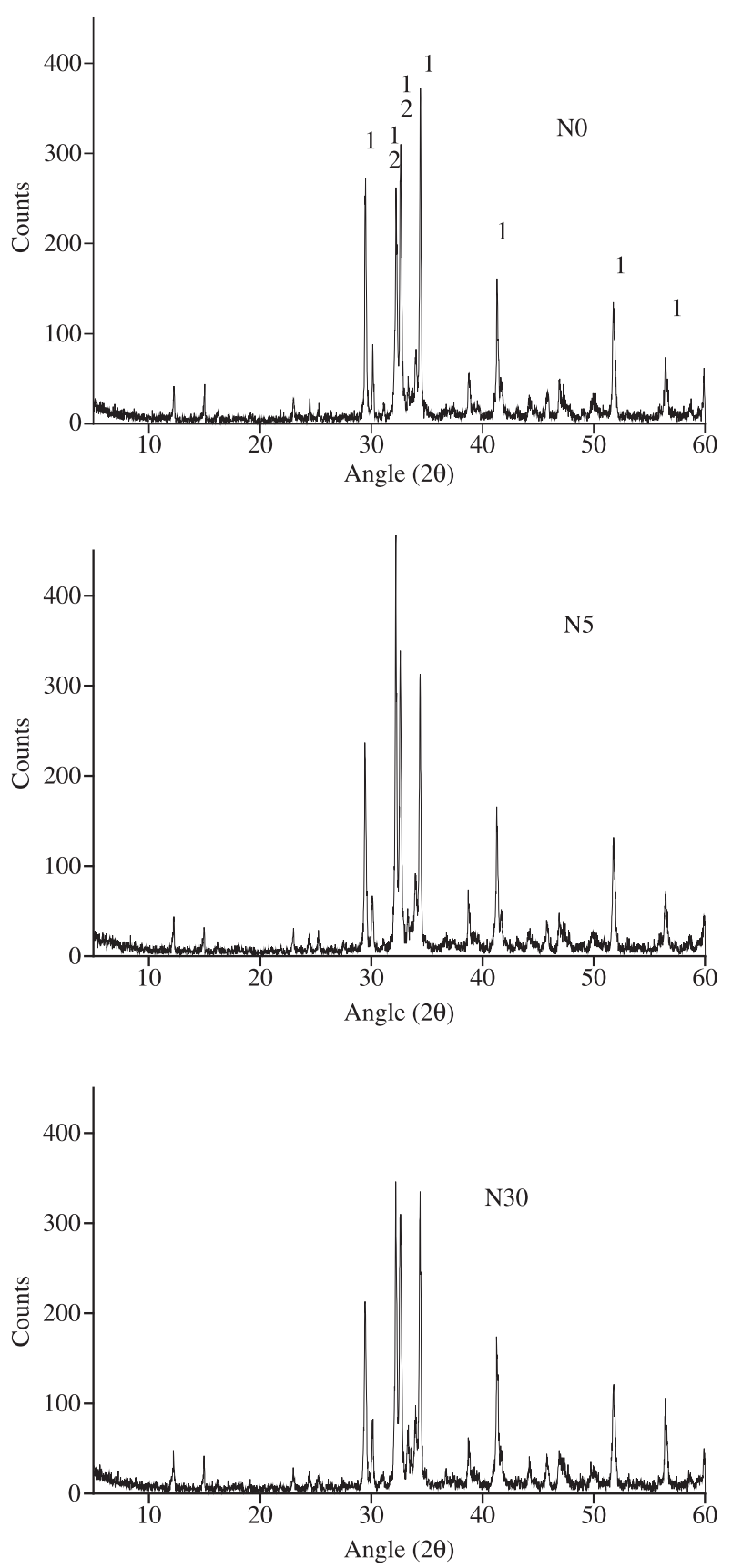

Figure 2. X-ray power diffraction of N0, N5 and N30 clinkers. $d=2.7769(2 \theta=32.20,70 \%)$, corresponding to the $\mathrm{C}_{2} \mathrm{~S}$ y $\mathrm{C}_{3} \mathrm{~S}$ phases. This inversion occurs in the whole series with added tire ashes, where the highest relative intensity is for $2 \theta=32.19$ with slight variations for $\mathrm{N} 5, \mathrm{~N} 10, \mathrm{~N} 20$ and $\mathrm{N} 30$. In N10, the highest relative intensity peak takes place for $2 \theta=32.62$.

In the clinkers with ashes, there were slight shifts of the main peaks of $\mathrm{C}_{3} \mathrm{~S}$. However, a growing increases in the values of $2 \theta$ (or decrease of d) with the growth of ashes tenor has not been observed, Table 4. There is a tendency up to determined ashes levels, from $\mathrm{N} 5$ to $\mathrm{N} 20(\mathrm{~d}=2.7786,2.7735,2.7731)$, which is then reversed for those tenors, $\mathrm{N} 30(\mathrm{~d}=2.7798)$. This is due to the possibility of crystalline structures of accepting up to a certain quantity of impurities as a solid solution, thus modifying the evaluated parameter. When certain level is exceeded, the faults generated can be different and consequently displace the values measured in opposite directions. The authors have already observed this phenomena with other impurity systems, such as car burnt oil ashes ${ }^{14}$.

\subsubsection{Pyrometric cone equivalent test}

Most transformations produced in cementitious materials during calcinations depend on heating time, temperature and impurity present. In order to study the behavior under the action of temperature, a pyrometric cone equivalent test was carried out. This test consists in modeling, with the material to be studied, some triangular-pyramid-shaped pieces (ASTM C24-86). This test cone, together with a standard one, is put under a specific heating rate in an oxidizing atmosphere. The PCE temperature is measured when the material softens and the cone end falls.

Even though the single measurement of the PCE temperature does not determine what occurs in the furnace, under equal conditions and in comparison with the reference, it gives us information on the effect of the impurities added to the system during clinkering. Results obtained are shown in Table 5.

The PCE temperature for the reference was of $1550{ }^{\circ} \mathrm{C}$, maintained in N5 and N10. When the percentage of ashes added corresponded to a replacement of $20 \%$ or more, the temperature increased. This would indicate that the impurities added determine a refractory effect in the system, increasing the softening temperature. Usually impurities can diminish the system fusion point, except with substances more refractory than the original sample. The $33 \%$ in weigh of the incorporated ashes corresponds to $\mathrm{ZnO}^{15-17}$ which fusion point is $1800{ }^{\circ} \mathrm{C}$. An increase on its tenor could be raising the fusion point and the sample viscosity, despite continuing performing as a mineralizer. This would lead to a growth of TCE. It is difficult to verify this supposition owing to the complexity of the oxide system considered.

\subsubsection{Specific surface measurement}

Clinker behaviour during milling is directly related to the texture and crystalline structure of the phases formed during clinkering ${ }^{18}$. Consequently, and considering the milling conditions stipulated in

Table 4. Location of the $\mathrm{C}_{3} \mathrm{~S} / \mathrm{C}_{2} \mathrm{~S}$ main peaks in different samples (d), and their corresponding relative intensities (I/I $\mathrm{I}_{0}$ ).

\begin{tabular}{ccccccccccc}
\hline & $\mathrm{N} 0$ & \multicolumn{2}{c}{$\mathrm{N} 5$} & \multicolumn{2}{c}{$\mathrm{N} 10$} & & $\mathrm{~N} 20$ & $\mathrm{~N} 30$ \\
\hline $\mathrm{d}$ & $\mathrm{I} / \mathrm{I}_{0}$ & $\mathrm{~d}$ & $\mathrm{I} / \mathrm{I}_{0}$ & $\mathrm{~d}$ & $\mathrm{I} / \mathrm{I}_{0}$ & $\mathrm{~d}$ & $\mathrm{I} / \mathrm{I}_{0}$ & $\mathrm{~d}$ & $\mathrm{I} / \mathrm{I}_{0}$ \\
\hline 3.0300 & 65 & 3.0325 & 47.6 & 3.0290 & 74.4 & 3.0290 & 48.9 & 3.0315 & 61.7 \\
2.7769 & 70.2 & 2.7786 & 100 & 2.7735 & 98.8 & 2.7731 & 100 & 2.7798 & 100 \\
2.7433 & 73.7 & 2.7458 & 68.7 & 2.7429 & 100 & 2.7425 & 74.3 & 2.7429 & 91.4 \\
2.6046 & 100 & 2.6071 & 66.4 & 2.6038 & 91.8 & 2.6038 & 61.7 & 2.6086 & 88.3 \\
\hline
\end{tabular}


Table 5. Pyrometric Cone Equivalent Temperature $\left({ }^{\circ} \mathrm{C}\right)$.

\begin{tabular}{cc}
\hline Sample & PCET $\left({ }^{\circ} \mathrm{C}\right)$ \\
\hline N0 & 1550 \\
N5 & 1550 \\
N10 & 1550 \\
N20 & 1564 \\
N30 & 1570 \\
\hline
\end{tabular}

Table 6. Blaine specific surface, $\mathrm{Se}\left(\mathrm{m}^{2} / \mathrm{Kg}\right)$.

\begin{tabular}{cc}
\hline Sample & Se \\
\hline N0 & 333 \\
N5 & 341 \\
N10 & 331 \\
N20 & 338 \\
N30 & 319 \\
\hline
\end{tabular}

this work (see 2.2.2), the highest specific surface values of the samples with tire ashes (Table 6) in relation with the reference (N5 and N20) indicate an easier milling. In N10 and N30, found the opposite effect, was obtained a lower specific surface than for the reference, which is attributed to the presence of more crystalline phases. Then, the effect produced by the addition of ashes to the crystalline structure is not a function of the percentage added, but it is undoubtedly caused by the presence of ashes that act as mineralizes (favoring the formation of crystalline phases) up to certain point when the effect reverts.

$\mathrm{N} 10$, as we could see before, has different in its crystalline structure. If N10 is excluded, the specific surface, within those added, decreases when increasing the percentage of ashes added.

\subsection{Study of clinkers during hydration}

\subsubsection{Differential calorimetric studies}

In order to study the material behavior during early hydration, the calorimetric curves corresponding to the first 48 hours of hydration of the different clinkers studied are shown in Figure 3. Differences in the starting hydration stage (first peak, at $<100$ minutes) can be attributed to differences in the initial surface activity, which could not be related to the percentage of ashes added.

That stage is followed by a period of apparent inactivity, known as "dormant period". The final of dormant period is correlated with the starting of the setting. Significant differences could be here observed in the different samples, a shorter dormant period means an evident decrease in the starting point of setting times.

The second maximum of the curves is correlated with the end of the setting times and the start of hardening ${ }^{19}$.

Two tendencies can found when analyzing the samples with tire ashes. In the first N5-N10 series it was observed that when increasing the percentage of ashes added, the start of the setting times moved forward in relation to N0, although the specific surface values obtained led to think contrarily. This would indicate that ashes influence the hydration rate, independently of the specific surface, which is usually a decisive factor at early ages.

The second series is composed by N20-N30. There are not significant differences between them as regards the start and end of setting times, although once more it is the lower specific surface (N30) which moves forward. In relation to N0, both move significantly forward. If the end of setting time is related along the time when the second

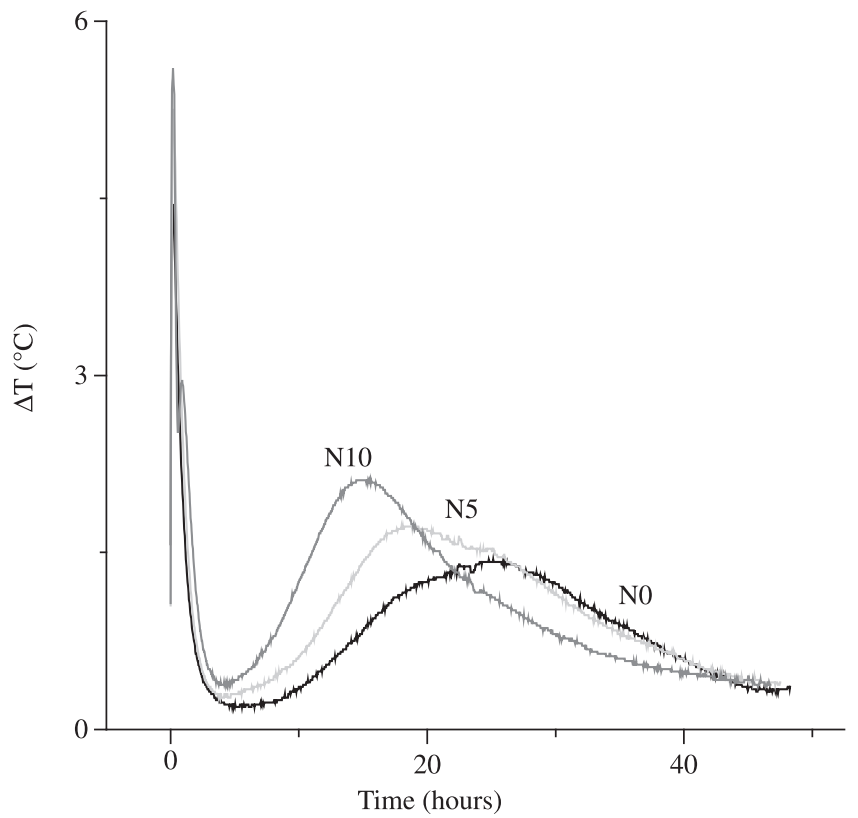

Figure 3. Calorimetric curves, first 48 hours of hydration.

Table 7. Leached Zn content of the 60 days hydrated samples

\begin{tabular}{lccc}
\hline Sample & \multicolumn{3}{c}{ Zn (ppm) } \\
\cline { 2 - 4 } & Incorporated (I) & Leached (L) & \% Retention (I-L)/I x100 \\
\hline N5 & 77.1 & 0.55 & 99.3 \\
N10 & 154.2 & 0.75 & 99.5 \\
N20 & 308.5 & 0.70 & 99.7 \\
N30 & 462.7 & 0.75 & 99.8 \\
\hline
\end{tabular}

maximum appears, $\mathrm{N} 10<\mathrm{N} 30<\mathrm{N} 20<\mathrm{N} 5<\mathrm{N} 0$ sequences is obtain. Ash addition obviously affected the early hydration rate, although this effect was not a direct function of the percentage added. On the contrary, the effect went in one sense up to certain percentage and then it inverted. Once again, N10 was the one which went out of the series, moving significantly forward start and end setting times.

\subsubsection{Lixiviation test}

In order to confirm the previous information, $\mathrm{Zn}$ and $\mathrm{Pb}$ lixiviation tests were performed on hydrated pastes for 60 days. Results obtained expressed as $\mu \mathrm{g} . \mathrm{L}^{-1}$ of leaching solution $(\mathrm{pH}=5$ solution and 18 hours of extraction) showed values lower than the detection limit of the technique $\left(<7 \mu \mathrm{g} . \mathrm{L}^{-1}\right)$ for the $\mathrm{Pb}$ case, and between 11 and $15 \mu \mathrm{g} . \mathrm{L}^{-1}$ for $\mathrm{Zn}$. The analysis was carried out by atomic emission spectroscopy by inductive coupled plasma (ICP). Table 7 summarizes the results of $\mathrm{Zn}$ lixiviation, corresponding to the $\mathrm{Pb}$ lixiviation are omitted since are $<7 \mu \mathrm{g} . \mathrm{L}^{-1}$. The results clearly indicating the metals retention in the silicate lattice.

As it can be deduced from earlier data, $\mathrm{Zn}$ is totally retained in the lattice without later mobilization risks. Leaching percentages $(\leq 1.1 \%$, Argentine law 24051, 1992) ${ }^{20}$ are below the limits considered risky to the health and the environment, and they coincide with what Shih reported for this metal ${ }^{13,21}$.

As regards $\mathrm{Pb}$, it was said that it can be accumulated in the clinker without an adverse effect if it is $<70 \mathrm{ppm}^{12}$; in this case (maximum addition $184 \mathrm{ppm}$ ), it would not run any risk in the clinker, nor in the 

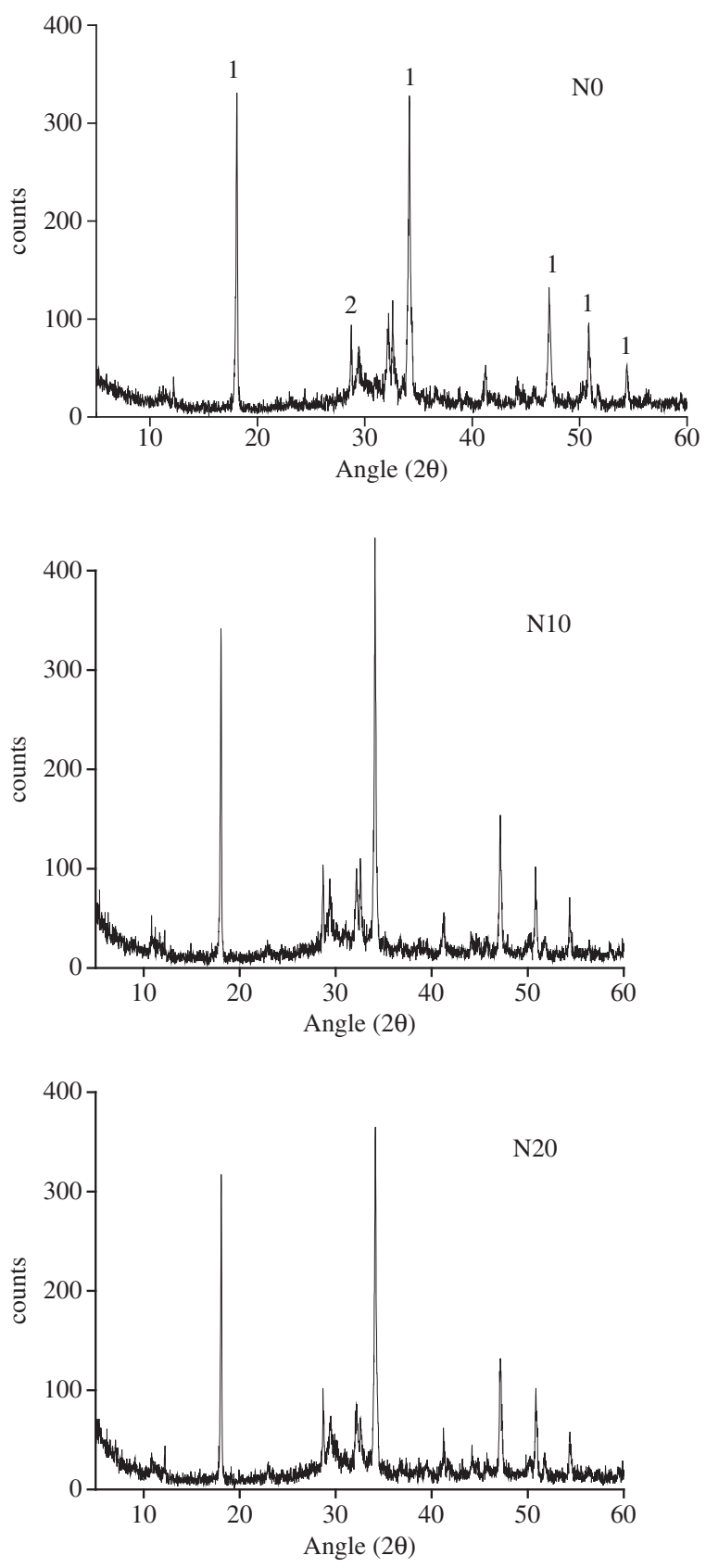

Figure 4. XRD of NO, N10 and N20 at 7 hydration days.

environment if it leached the whole amount added to it (admit drinking water $50 \mu \mathrm{g} . \mathrm{L}^{-1}$ maximum, Argentine Law 24051, 1992) ${ }^{20}$.

\subsubsection{XRD analysis}

In order to complete the studies, hydration was monitored by XRD up to 60 days. When analyzing the diffractograms of hydrated clinkers at different ages, no differences with $\mathrm{N} 0$ were observed that could indicate the formation of new phases related to or inhibited by the presence of ashes. The semi-quantitative study following of the hydration rate was carried out through the relative intensity of the main peaks of $\mathrm{Ca}(\mathrm{OH})_{2}$ formed during hydration and the silicates ones $(2 \theta=34.085)$. Comparatively, it can be observed a greater advance of the hydration in N10 and N20 samples in relation to N0, confirming the tendency reported by differential calorimetry at first

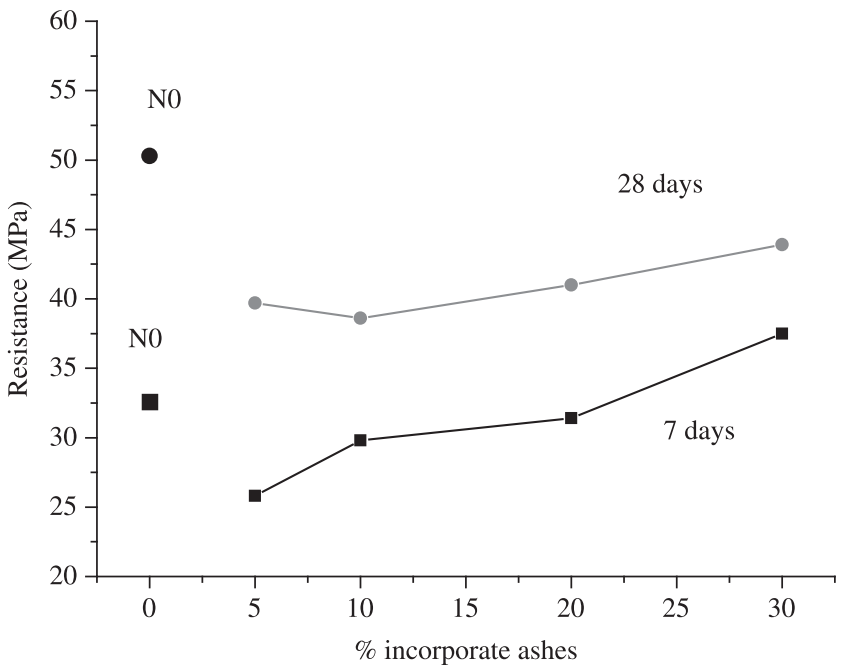

Figure 5. Compression resistance of the samples after different hydration times $[\mathrm{MPa}]$.

48 hours of hydration. As and example Figure 4 comparatively shows the diffractograms obtained for the hydrated samples for 7 days. At different ages of hydration (1-60 days) the results show the same tendency are omitted in the Figure 4.

\subsubsection{Compressive strength}

The obtained average of compressive strength in five tests after 7 and 28 days appears in Figure 5.

After 7 days, the strength of test samples increased with the percentage of ashes added. However, only N30 exceeded the reference.

Within samples with tire ashes addition, a strength increase occurred after 28 days according to the percentage added. An inversion between N5 and N10 only occurred after 28 days. We have observed a similar effect in other studies ${ }^{14}$. The addition of impurities to the system created a mineralizer effect that improved the properties expected. But this effect does not always depend on the percentage added.

When analyzing the results after 28 days of hydration, N0 presented strength values higher than all the series studied. Values obtained were significantly lower, which poses a serious problem in the use of the material obtained in that way. This effect was the only adverse one in the present study, but it has been already reported for $\mathrm{ZnO}>0.3 \%$ addition in weight ${ }^{15}$.

\subsubsection{Porosymmetrical distribution}

The strength results previously presented after 28 days can be related to those obtained for porosymmetrical distribution.

The size distribution curves of pores after 28 days for the samples N0, N5 and N30 are shown in Figure 6 (30 - $50000 \AA)$.

$\mathrm{N} 5$ and $\mathrm{N} 30$ curves are alike, but different to the reference N0. Although N30 distribution is different to N0, they follow a similar distribution course away from N5, as it is shown in Figure 6.

This agrees with the mechanic strength values measured at the same age where minimum resistance is observed for N5, which shows a higher porosity in all the range.

\section{Conclusions}

- Tire ashes added during clinkering introduced substances that produce modifications in the microstructure as shift and inversion of relative intensities of main peaks of silicates; 


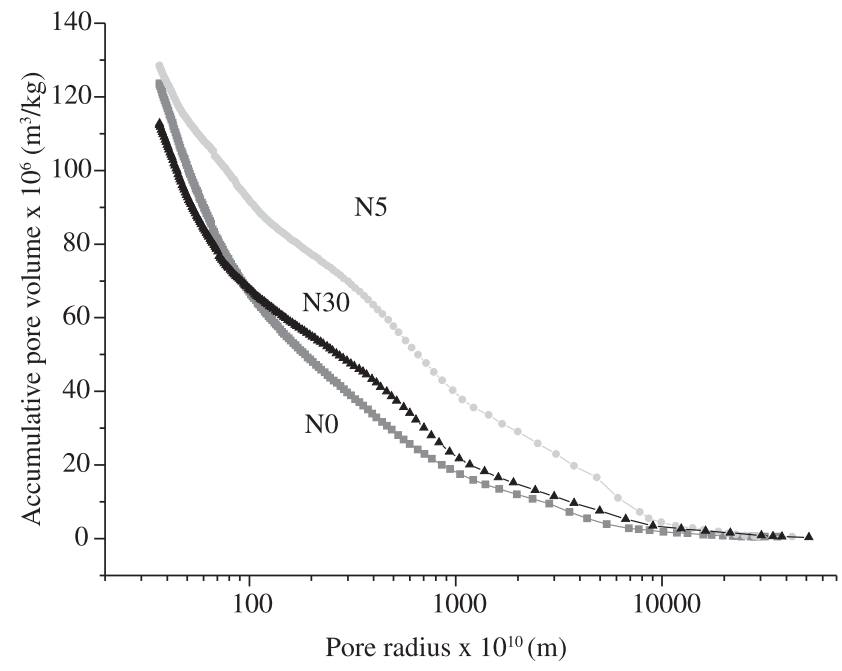

Figure 6. Pore size distribution of N0, N5 and N30 samples hydrated for 28 days.

- Milling clinker with different ashes levels show a non-linear specific surface area in relation to the addition level used. The energy requirement to reach the same fineness in milling showed a general tendency to decrease with the increase of addition concentration. The ashes added seen to modify clinkers hardness, mainly when there is a low or a high concentration of them;

- The calorimetric study shown that the incorporated ashes accelerated the hydration rate (start and end) in relation to N0. In the studied percentages, N10 have showed the minimum setting time;

- Lixiviation tests clearly indicated that the Portland cement matrix is a suiTable place for the solidification/stabilization of the oxides, metals added through the tires.

- The XRD hydration monitoring did not show the formation of any hydration product different to those present in the reference. Only slight differences in the early hydration rate can be mentioned; and

- Values of compression strength obtained after 7 and 28 days decreased highly in the study samples in relation to the reference. Values obtained at both ages for the samples with ashes are related to the percentage incorporated (generally, the higher the percentage, the higher the compression strength and this could be related to the porosymmetrical distribution.

\section{References}

1. Instituto Nacional de Estadísticas y Censos de la República Argentina, INDEC. Estadística de productos industriales, 2008. Available from: http://www.indec.mecon.gov.ar

2. Siddique R and Naik TR. Properties of concrete containing scrap-tire rubber - an overview. Waste Management. 2004. 24(6):563- 569.
3. Fattuhi NI and Clark LA. Cement-based materials containing shredded scrap truck tire rubber. Construction \& Building Materials. 1996; 10(4):229-236.

4. Pera J, Ambroise J and Chabennet M. Valorization of automotive shredder residue in bulding materials. Cement and Concrete Research. 2004; 34(4):557-562.

5. Amari T, Themelis N and Wenick IK. Resource Recovery from Used Rubber Tires. Resources Policy. 1999; 25:179 - 188.

6. Scrap Tires Management Council. The used of scrap tires in cement rotary kilns. Washington DC; November 1992.

7. Stephan D, Maleki H, Knöfel D, Eber B and Härdtl R. Influence of the $\mathrm{Cr}, \mathrm{Ni}$ and $\mathrm{Zn}$ in the properties of pure clinker phases: Part I. $\mathrm{C}_{3}$ S. Cement and Concrete Research. 1999; 29(4):545-552.

8. Taylor HFW. La química del cemento. (in spanish). Enciclopedia de la Química Industrial. Bilbao, España: Ed. Urmo; 1971.

9. Stephan D, Mallmann R, Knöfel D and Härdtl R. High intakes of Cr, Ni and $\mathrm{Zn}$ in clinker: Part I. Influence on burning process and formation phases. Cement and Concrete Research. 1999; 29(12):1949-1957.

10. Stephan D, Mallmann R, Knöfel D and Härdtl R. High intakes of Cr, Ni and $\mathrm{Zn}$ in clinker: Part II. Influence on the hydration properties. Cement and Concrete Research. 1999; 29(12):1959-1967.

11. Asavapisit S, Fowler G and Cheeseman CR. Solution chemistry during cement hydration in the presence of metal hydroxide waste. Cement and Concrete Research. 1997; 27(8):1249-1260.

12. Dalton JL, Gardner KH, Seager TP, Weimer ML, Spear JCM and Magee BJ. Properties of Pórtland cement made from contaminated sediments. Resources, Conservations and Recycling. 2004; 41(3):227-241.

13. Shih PH, Chang JE, Lu HC and Chiang LC. Reuse of heavy metalcontaining sludges in cement production. Cement and Concrete Research. 2005; 35(11): 2110-2115.

14. Trezza MA and Scian AN. Burning wastes as an industrial resource: their effect on Pórtland cement clinker. Cement and Concrete Research. 2000; 30(1):137-144.

15. Odler I and Schmidt O. Structure and properties of Pórtland cement clinker doped with ZnO. Journal of the American Ceramic Society. 1980; 63(1):13-16.

16. Bordoloi D, Baruah ACH, Barkakati P and Borthakur PCH. Influence of $\mathrm{ZnO}$ on clinkerization and properties of VSK cement. Cement and Concrete Research. 1998; 28(1):329-333.

17. Kakali $\mathrm{G}$ and Parissakis G. Investigations of the effect of $\mathrm{Zn}$ oxide on the formation of Pórtland cement clinker. Cement and Concrete Research. 1995; 25(1):79-85.

18. Tsivilis S and Kakali G. A study on the grindability of Pórtland cements clinker containing transition metal oxides. Cement and Concrete Research. 1997; 27(5):673- 678.

19. Alumno Rosetti $V$ and Medici I. Inertization of toxic metals in cement matrices: effects on hydration, setting and hardening. Cement and Concrete Research. 1999; 25(6):1147-1152.

20. Argentine Law 24051: Residuos peligrosos - generación, manipulación, transporte y tratamiento. Normas (1992). Decreto 831/93. Argentina; 1992. (in Spanish).

21. Deja J. Immobilization of $\mathrm{Cr}^{6+}, \mathrm{Cd}^{2+}, \mathrm{Zn}^{2+}$ and $\mathrm{Pb}^{2+}$ in alkali-activated slag binders. Cement and Concrete Research. 2002; 32(12):1971-1979. 